\title{
An Integrated Model to Capture the Provision of Health and Social Care Services Based on the ContSys and FHIR Standards
}

\author{
Fabrizio Pecoraro, Daniela Luzi, Fabrizio L Ricci \\ Institute for Research on Population and Social Policies, National Research Council, Rome, Italy
}

\begin{abstract}
In the last decades, there is a shift in the provision of health services from the formal facilities to home care. The delivery of care at home is considered a sustainable approach that not only results in substantial cost savings but is also a key step towards achieving optimal outcomes in the delivery of high-quality health services. Moreover, the adoption of this approach is facilitated by the prompt development of medical and non-medical technologies that can simplify care coordination and enable distant monitoring of the patient. However, home care requires the integration and coordination of health and social stakeholders in a continuity of care perspective. This requires the adoption of standards to define a common shared conceptual model
\end{abstract}

\section{Correspondence to:}

Fabrizio Pecoraro

Institute for Research on Population and Social Policies, National

Research Council, Via Palestro, 32 - 00185 - Rome, Italy

E-mail: f.pecoraro@irpps.cnr.it that improves the interoperability among information systems and organizations. In this paper to accomplish this task we combine the ContSys standard and the HL7 FHIR (Fast Healthcare Interoperability Resources) framework to identify concepts to be exchanged between systems, organizations and providers involved in the health and social context. This model has been developed to improve the integration and coordination of social and health care services within the Italian $\mathrm{H} @ H$ project.

\section{Keywords}

Continuity of care; Integrated care; Home care; ContSys standard; HL7 FHIR

EJBI 2017; 13(1):17-26

received: May 31, 2017

accepted: July 20, 2017

published: October 10, 2017

\section{Introduction}

The demographic, epidemiological and social changes related to a growing number of older people with an increased incidence of multiple chronic conditions and of functional and cognitive impairments are leading to an increased demand of health and social service integration at home [1]. This has led also many European countries to adopt policies to strongly shift the organization and provision of health and social services from formal institutional facilities (e.g. hospitals) to home care $[2,3,4]$. This is considered a sustainable approach that results in a substantial cost savings $[5,6,7,8]$ mainly preventing unnecessary or long-term hospitalizations [7]. Moreover, it supports patients with chronic illness as well as temporarily frail individuals in a protected and comfortable environment [9] in line with patient preferences to be cared in their own home $[4,10,11]$. It provides appropriate and high-quality care services also considering the support of informal caregivers (e.g. family members), with the use of appropriate technologies $[2,12]$, such as those developed within the Ambient Assisted Living (AAL) program [3]. The rapid development of medical and non-medical technologies together with new and modern organization of health and social service delivery can represent a viable solution to develop home care provided that healthcare systems further enhance integration and support coordination [3] with social services, such as house cleaning, home maintenance, shopping, and transport.

The integration of health and social services within a home care delivery model needs the connection between the health care and the social systems taking into account their specific characteristics [3]. However, a common criticism of home and community services offered by different providers is that they are fragmented, resulting in poor outcomes and wasted resources [5]. For this reason there is a need to improve coordination and cooperation among stakeholders both in a vertical (e.g. primary and secondary care) and a horizontal perspectives (e.g. health and social care) taking also into account the different needs of the target population (e.g. elderly, temporarily fragile, healthy people). To accomplish this task one of the first issues that should be 
overcome is the definition of a common shared conceptual schema developed using standardized data models as well as common vocabularies and nomenclatures.

In this perspective one of the most widely used framework to improve the continuity of care and to enable communication between different information systems is the ContSys [13] standard that provides a set of concepts to describe both the content and context of the health services provided in a patient-centred care delivery. Moreover, among the different standards developed in healthcare to facilitate system interoperability and under the perspective of data models HL7 [14] surely represents one of the main candidates for the integration and exchange of information [15] generally focused on patient's care delivery. A relatively recent standard released by HL7 is the FHIR (Fast Healthcare Interoperability Resources) language that is considered to be the most promising candidate standard framework for the exchange of healthcare information [16]. As reported in the HL7 website [16], "the philosophy behind FHIR is to build a base set of resources that, either by themselves or when combined, satisfy the majority of common use cases. FHIR resources aim to define the information contents and structure for the core information set that is shared by most implementations".

This solution has been adopted within the Health At Home (H@H) project with the aim of developing an open platform that provides a technological and organizational solution based on integrated and interoperable software services as well as Internet of Things. This paper describes the $\mathrm{H} @ \mathrm{H}$ project focusing on its architecture and proposes a conceptual model as a result of a first step that combines the use of the ContSys standard to define a shared integrated conceptual model with the FHIR standard release 3 (STU) that can facilitate the semantic interoperability among systems and organizations.

\section{The H@H Project Infrastructure}

$\mathrm{H} @ \mathrm{H}$ project provides a technological and organizational solution to support both subjects of care and organizations that deliver health and social services at home based on integrated and interoperable software services and Internet of Things (e.g. devices). Examples of health services are remote monitoring of vital signs and body measures, telemedicine, home visits provided by specialists, primary care professionals; examples of social services are household maintenance, meal preparation, personal care activities. The overall purpose of the H@H infrastructure is to improve the "quality of life" of citizens/families which have temporary or permanent "weaknesses" or health care assistance and the remote monitoring of chronic patients in outpatient settings.

In Figure 1, a high-level architecture of the project is shown [17], where the primary focus is on the user who accesses to a set of services interacting with a cluster of sensors that monitor user's vital signs, environmental parameters, user lifestyle, etc. These devices can be placed at home (e.g. temperature and humidity, motion and occupancy, flood and leak sensors) and/or worn by the user (e.g. fitness tracker, fall monitor, blood pressure measurement). Further data are produced by other cluster of sensors to enrich the home setting monitoring activities carried out by the user outside

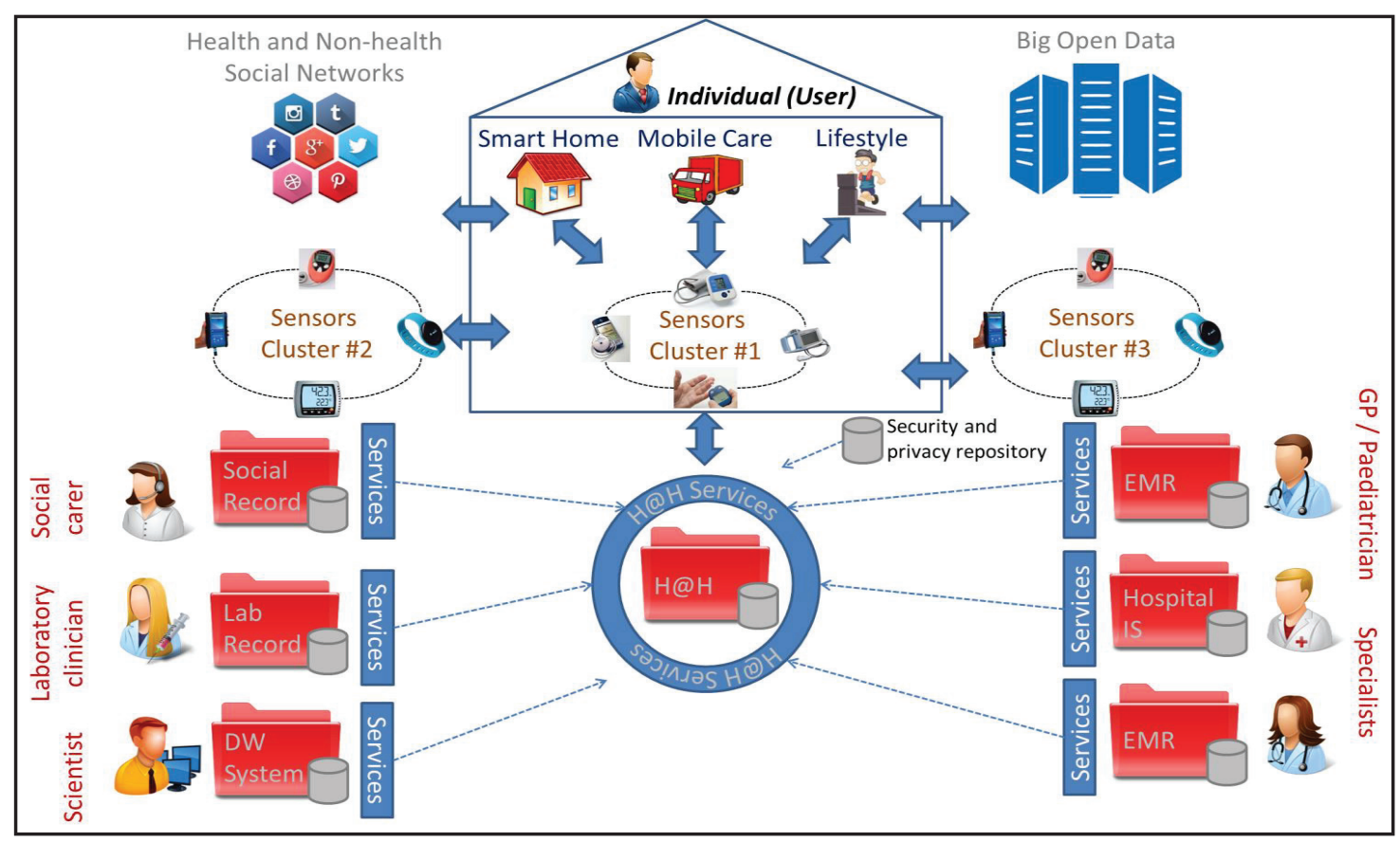

Figure 1: Architecture of the $\mathrm{H} @ \mathrm{H}$ project at high-level of description. 
home or to capture other contextual information, such as weather conditions and forecast, transport facilities. Data provided by these sets of clusters are gathered in different databases composing the $\mathrm{H} @ \mathrm{H}$ system and are interoperable with information provided by different information systems managed by social and health care providers, such as the General Practitioner and specialist Electronic Health Records, Hospital and Laboratory Information Systems, Electronic Social Record. The interaction and data exchange are executed through a set of web services developed on the basis of the cloud computing paradigm. An important set of functionalities provided by this platform concerns the real-time monitoring of data coming from sensors and information systems and their communication to an operating centre that is responsible to identify and manage alerts and periodical measurements of functional parameters of the devices. Moreover, a data warehouse (generated by export functionality applied on current databases) is foreseen to analyse data for secondary purposes in a clinical governance framework to evaluate the effectiveness and appropriateness of the provision of health and social services and others uses (epidemiology, clinical researches, education, etc.) [18]. Privacy and security services are also considered to manage rules to be applied to manage databases and feed the data warehouse.

The platform is a robust and flexible Cloud Services Framework designed to be easily customizable through the use of JAVA and XML technologies. These characteristics will allow to easily extend the data domain and to provide the immediate remote access to data. Furthermore, it will interact with other distributed technologies including SQL and NoSQL (e.g. object and document oriented) databases.

\section{Materials and Methods}

This section describes the steps of the methodology adopted to define a conceptual model that integrates both health and social services as well as the mapping procedures implemented to represent these concepts with the resources of the HL7 FHIR standards. In particular the first step is to define the health model by selecting the main concepts from the ContSys standard that fit the purposes of the $\mathrm{H} @ \mathrm{H}$ project. Starting from this model, the second step is to detect the main concepts that can be shared with the social model to define an abstract core backbone that can link both the health and social schemas. This meta-model is the starting point to define the social schema identifying the concepts specifically needed in the social care context. The third step is to define the integrated model where the health and social care concepts are compared and mapped with the FHIR resources in the final step of the methodology.

\subsection{Definition of the Health Conceptual Model}

In this first step of the proposed methodology the main concepts that fit the purposes of the health part of the $\mathrm{H} @ \mathrm{H}$ project are identified. This selection is based from the concepts presented in the ISO 13940 (also known as ContSys) [13] that is an important and widely used standard in the provision of a common conceptual model for continuity of care [19] as well as to facilitate the communication between different information systems at the semantic level. This model meets the identified requirements of the H@H project where the continuity of care is one of the main tasks to be accomplished. The ContSys standard, which includes approximately 84 concepts organized into eight areas closely related to each other, is needed to represent both the content and context of the healthcare services delivered. Its aim is to define a common conceptual framework to describe generic concepts that represent both the content and context of the health services provided during the interaction between a subject of care and health professionals in a patient-centred care delivery.

\subsection{Definition of the Social Conceptual Model}

Given that there are not common standards in social care that play a significant role in the identification of a conceptual model to improve the interoperability among systems and organizations, to identify the main concepts of the social schema we firstly identify a meta-model composed by a set of ContSys concepts that can be shared with the social model to achieve an abstract description of a generic activity as well as the different concepts needed to describe it. Once this abstraction is performed to identify additional concepts needed to describe the social context, the different types of social services to be provided at home to support the subject of care and/or the family are analysed on the basis of a set of regional, national and European nomenclatures. This is an important step of the methodology considering that, even if social care is an important determinant of care [20], its activities are not included in the ContSys standard.

\subsection{Definition of the Integrated Model}

Once both models have been defined, the subsequent step of the methodology is to propose a conceptual model able to capture the interaction between the individual and the professionals in the provision of health and social service at home in a continuity of care perspective. To accomplish this task each concept is classified within the following categories taking into account its definition as well as the information gathered:

1. Shareable concepts that are in common between the health and social models. 
2. Generalized concepts that are represented using similar classes in both models and that can be related with ISA relationship.

3. Concepts that are modelled only in one context (e.g. social care) but that can be included in the other one (e.g. health care).

4. Specific concepts that are explicitly used in one model and that are not needed in the other one.

\subsection{Mapping of the Integrated Model with the} FHIR Schema

In this final step, each concept of the integrated model has been subsequently mapped with the resources of the FHIR model, identifying in particular:

1. Classes that directly mapped with the resources of the FHIR (same semantic of the class as well as attributes).
2. Resources of the FHIR to be accommodated to map the classes of the conceptual model in terms of: semantic as well as vocabulary and nomenclatures type to be modified.

3. Resources of the FHIR to be extended to map the classes of the conceptual model in terms of: attributes to be added, associations with other resources to be added.

This mapping exercise can be considered as a test to verify to what extent the two standards can be integrated to facilitate the information exchange in a continuity of care perspective.

\section{Results}

In this section the results of the above described steps of the methodology are reported.

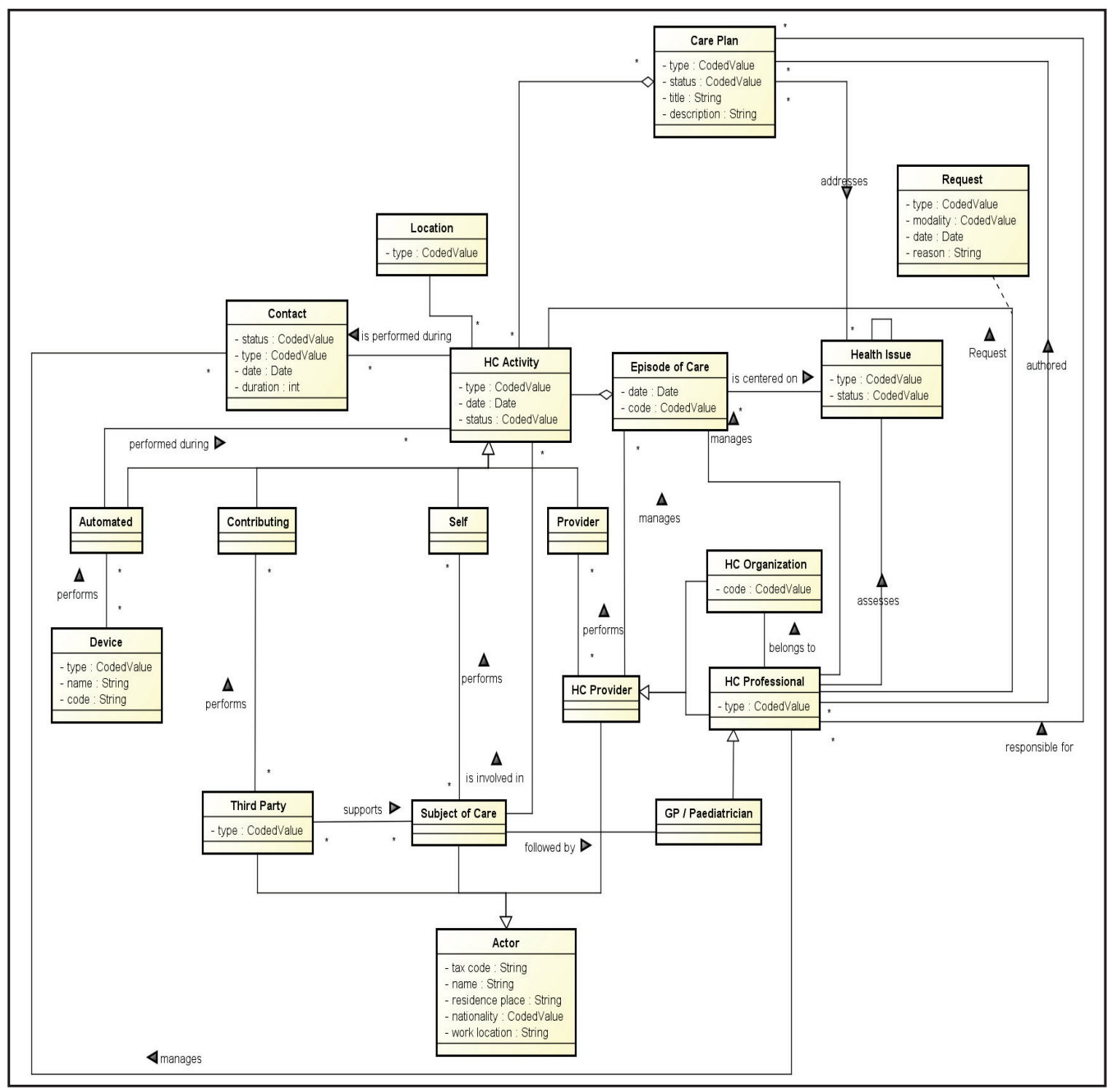

Figure 2: Healthcare conceptual model. 


\subsection{Healthcare Conceptual Model}

The result of the first step of the methodology is shown in Figure 2 using the UML class diagram. It highlights: (i) the main concepts of the ContSys standard (i.e. activity, contact, episode of care, health issue); (ii) the main actors involved (i.e. subject of care, healthcare provider, third party such as a family member); (iii) the device and the location.

In particular the main classes are summarized in Table 1 reporting the related definition on the basis of the ContSys standard. As described in the standard document [13] healthcare is delivered through a set of Healthcare Activities that are performed in a Location, that may be required by a Healthcare Professional and included within a specific Care Plan. These activities are provided within a specific time interval (Episode Of Care) during which a Health Issue of the Subject of Care is addressed. Moreover, these set of activities are performed during a specific encounter (Contact) where the Subject of Care interacts directly or indirectly with one or more Healthcare Professionals. Note that an Healthcare
Activity can be performed not only by a Healthcare Provider but also conducted directly by the Subject of Care (e.g. measuring the blood pressure), by a Third Party who is responsible for supporting the Subject of Care (e.g. a family member who executes the haemoglobin glycated test) or by a Device without the intervention of a human being (e.g. Holter).

\subsection{Social Care Conceptual Model}

As highlighted in the previous paragraph the core concept of the health model based on the ContSys standard is the activity that is posed at the centre of the model and connected to five main concepts: Health Issue to detect why the activity is performed; Subject Of Care and Healthcare Provider to specify who is involved in the performance of the activity as well as the related Organization; Location to identify where the activity is performed; Care Plan to specify the activities, objectives and goals related to specific health issues of the Subject Of Care. It is important to note that a generalization of the backbone of the health schema is needed to be integrated in the corresponding concepts of the social part of the conceptual model, as shown in Figure 3.

Table 1: List of health related concepts modelled within the H@H schema.

\begin{tabular}{|c|c|}
\hline Class & Definition as reported in the ContSys standard \\
\hline Healthcare Activity & Activity intended directly or indirectly to improve or maintain a health state. \\
\hline Healthcare Provider Activity & Healthcare activity performed by a healthcare provider. \\
\hline Self-care Activity & Healthcare activity performed by the subject of care. \\
\hline Healthcare Contributing Activity & Healthcare activity performed by a healthcare third party \\
\hline $\begin{array}{l}\text { Automated Activity } \\
\text { (Automated Healthcare) }\end{array}$ & $\begin{array}{l}\text { Method of delivering healthcare initiated by a responsible healthcare actor and thereafter } \\
\text { delivered automatically by an automatic medical device }\end{array}$ \\
\hline Care Plan & $\begin{array}{l}\text { Dynamic, personalized plan including identified needed healthcare activities, health objectives } \\
\text { and healthcare goals, relating to one or more specified health issues in a healthcare process }\end{array}$ \\
\hline Contact & Interaction between a subject of care and one or more healthcare personnel. \\
\hline Location $=$ Point of care & Location / point of care where direct healthcare activities are performed \\
\hline Episode of care & $\begin{array}{l}\text { Health related period during which healthcare activities are performed to address one health } \\
\text { issue as identified by one healthcare professional }\end{array}$ \\
\hline Health issue & $\begin{array}{l}\text { Representation of an issue related to the health of a subject of care as identified by one or more } \\
\text { healthcare actors. } \\
\text { See also Health condition: observed or potential observable aspects of the health state at a given } \\
\text { time. }\end{array}$ \\
\hline Healthcare Actor & Organization or person participating in healthcare \\
\hline Healthcare Provider & $\begin{array}{l}\text { Healthcare actor that is able to be assigned one or more care period mandates. It can be a } \\
\text { professional or an organization. }\end{array}$ \\
\hline Healthcare Professional & $\begin{array}{l}\text { Healthcare personnel having a healthcare professional entitlement recognized in a given } \\
\text { jurisdiction. }\end{array}$ \\
\hline Healthcare Organization & $\begin{array}{l}\text { Healthcare provider having an organization role. } \\
\text { See also healthcare provider = healthcare actor that is able to be assigned one or more care } \\
\text { period mandates }\end{array}$ \\
\hline Subject of Care & $\begin{array}{l}\text { Healthcare actor with a person role; who seeks to receive, is receiving, or has received } \\
\text { healthcare }\end{array}$ \\
\hline Third Party & $\begin{array}{l}\text { Healthcare actor other than a healthcare provider or the subject of care. Relative (family } \\
\text { member) aiding the subject of care, any actor responsible for social support, or for the funding, } \\
\text { payment, or reimbursement of healthcare provision are healthcare third parties. }\end{array}$ \\
\hline Device $=$ Automatic medical device & Medical device capable of performing automated healthcare activities \\
\hline General Practitioner & $\begin{array}{l}\text { Additional health concept not included in the ContSys standard that describes a specific } \\
\text { healthcare professional who plays the role of care giver of the Subject of care. }\end{array}$ \\
\hline
\end{tabular}




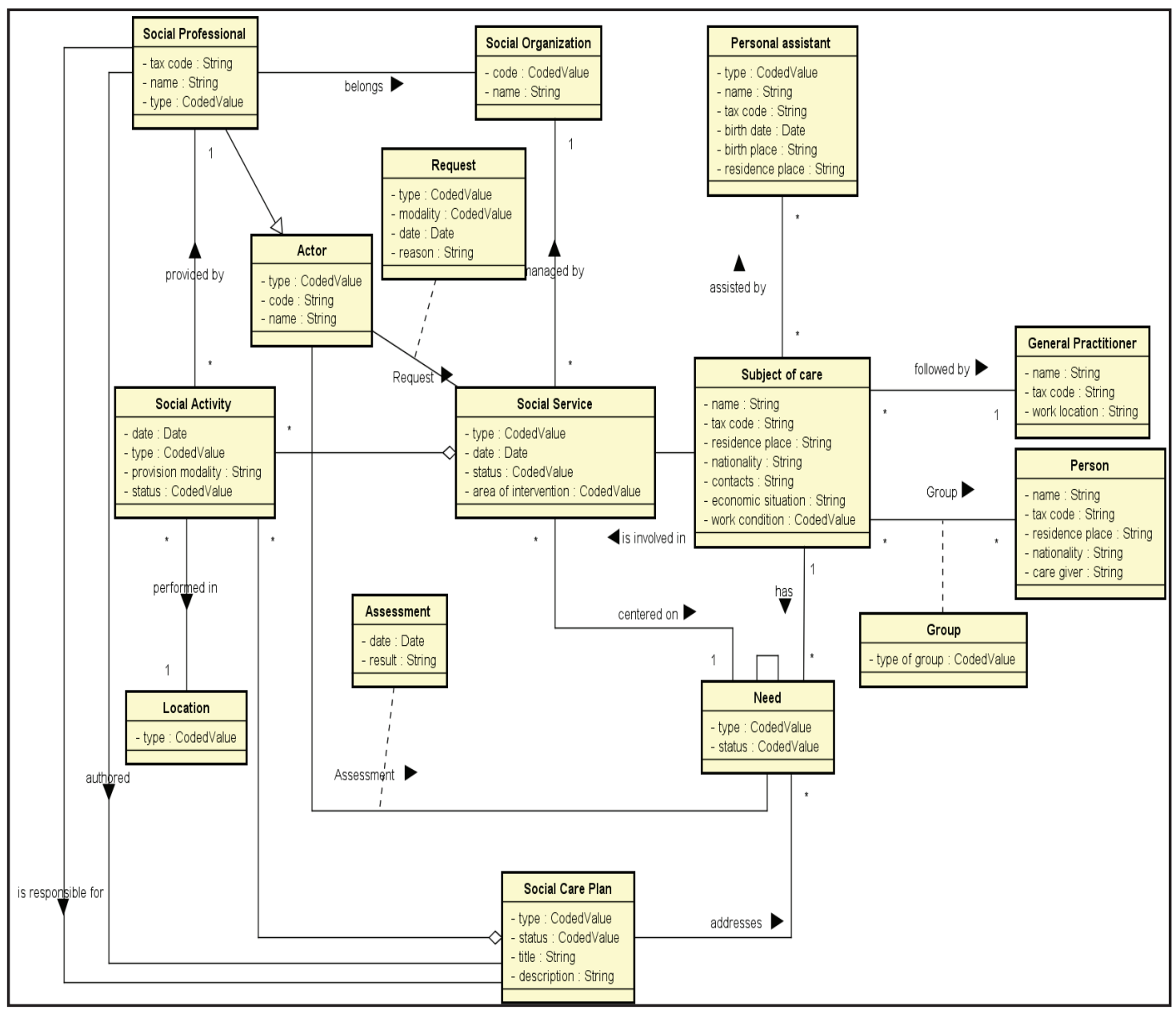

Figure 3: Social care conceptual model.

The core concept of the model is the Social Activity, performed by a care professional in a specific Location (e.g. home of the subject of care). A set of social activities are provided within an overall Social Service that is required by an Actor (that can be either a social or a health care professional) and focused on a specific Area of Interest (elderly, disable, minority, family, migration, poverty, mental health, etc.) and on a specific Need (economic, employment, health, house, educational, etc.). Each Need is assessed by an Actor who determine whether the patient is eligible to access the relevant social services. Each Subject of Care can be involved in many social services each one provided by a specific Provider Organization. As social services are provided also to a group of persons (even if associated to a specific subject of care), the conceptual model describes the membership of the Subject of Care to a family or a social network composed by a set of Persons (e.g. wife/husband, children, brothers/sisters, etc. as well as roommates, neighbours, friends, etc) also highligthing if a care giver can be detected among these persons. Finally, the subject of care is related with his/her General Practitioner.
Table 2: List of concepts that are shared between health and social conceptual model.

\begin{tabular}{ll}
\hline Concept & Comments \\
\hline Subject of care & The ID can be different in health and social care. \\
Location & No differences between health and social models. \\
Actor & No differences between health and social models. \\
\hline
\end{tabular}

\subsection{Integrated Model}

As reported in the methodology, prior to define the integrated schema a mapping between the health and social concepts has been performed and the results of this analysis is reported in Tables 2-5 highlighting, respectively, sharable, generalizable and extendable concepts as well as those that are specifically devoted for one context and not included in the other one.

The concepts reported in Table 2 represent the main elements that are used to describe an activity carried out in both health and social contexts.

Each of the concepts reported in Table 3 has a particular specification that assumes a specific meaning within the context where it is applied. For instance, both the Care plan 
and the Social care plan are referred to the abstract concept of plan (i.e. workflow) which is intended to describe the set of activities performed by a provider in a time sequence. This concept is specialized in each of the two contexts to capture the specificity of the health and the social part of the plan.

Each of the concepts reported in Table 4 has an important role to describe the context of reference. Although these concepts have not been considered in the model of the other context, they can be used to enrich it and to specify additional useful information. For instance, the Contact which is a medical concept, can be also used from a social perspective to collect all the relevant Social activities performed during a specific encounter between the Subject of care and a Social professional.
The concepts reported in Table 5 are specifically adopted by one of the two contexts and not included in the other one given that they seem to have a little use in it. For this reason, in this mapping procedure we do not extend it in different contexts, as evident considering the Health issue and the Social need classes.

\subsection{Mapping of the Integrated Model with the FHIR Schema}

Once the conceptual model is defined, this step provides the result of a mapping procedure between the concepts of the schema with the resources of the FHIR standard. In particular Tables 6-8 highlight, respectively, resources

Table 3: List of health concepts that are generalizable to be included in the social conceptual model.

\begin{tabular}{|c|c|c|}
\hline Health concept & Social concept & Comments \\
\hline Healthcare Provider & Social care Provider & $\begin{array}{l}\text { Representing in both context a professional or an organization that delivers / } \\
\text { manages or is generally involved in an activity. }\end{array}$ \\
\hline Healthcare Professional & Social care Professional & $\begin{array}{l}\text { Representing in both context a professional that delivers / manages or is } \\
\text { generally involved in an activity. }\end{array}$ \\
\hline Healthcare Organization & Social care Organization & $\begin{array}{l}\text { Representing in both context an organization that delivers / manages or is } \\
\text { generally involved in an activity. }\end{array}$ \\
\hline Healthcare Activity & $\begin{array}{l}\text { Social Activity }+ \text { Social } \\
\text { Service }\end{array}$ & $\begin{array}{l}\text { Same concept to be generalized to capture difference in the attribute list (and } \\
\text { coded values) as well as in the association with the provider. }\end{array}$ \\
\hline Care plan & Social care plan & $\begin{array}{l}\text { Same concept to be generalized to capture difference in the attribute list (and } \\
\text { coded values) as well as in the association with the provider. }\end{array}$ \\
\hline
\end{tabular}

Table 4: List of concepts that are included within a context and that can be also adopted in the other model.

\begin{tabular}{|c|c|c|}
\hline Concept & Context & Comments \\
\hline General Practitioner & Social & $\begin{array}{l}\text { This concept is adopted in the social care model to determine who is responsible for the health part of } \\
\text { the patient's care. Even if ContSys this association is not modelled, it can be a useful information also } \\
\text { in the healthcare model. }\end{array}$ \\
\hline Third party & Health & $\begin{array}{l}\text { This concept is adopted to determine who performs the third party activities as well as to identify who } \\
\text { supports the subject of care, and can be used to specify who is the care giver of the subject of care within } \\
\text { the social care perspective. }\end{array}$ \\
\hline Episode of care & Health & $\begin{array}{l}\text { This concept is adopted to group a set of activities performed for a specific health issue. It can be used } \\
\text { also to specify which are the social activities provided for the same episode of care. }\end{array}$ \\
\hline Contact & Health & $\begin{array}{l}\text { This concept is adopted to capture the encounter between the subject of care and an healthcare } \\
\text { professional grouping the set of activities performed in that specific consultation. It can be used also } \\
\text { to specify which are the encounters between the subject of care and the social professionals. Of course } \\
\text { attributes relevant for the social care have to be determined and included. }\end{array}$ \\
\hline
\end{tabular}

Table 5: List of concepts that are included within a specific context and that are not suitable in the other model.

\begin{tabular}{lll}
\hline \multicolumn{1}{c}{ Concept } & \multicolumn{1}{c}{ Context } & \multicolumn{1}{c}{ Comments } \\
\hline Other Person and Group & Social & $\begin{array}{l}\text { The concept Other person is used in the social model to associate the subject of care with } \\
\text { other persons in a specific Group (e.g. family, working group). These concepts seem to have } \\
\text { a little use in the health context especially under a patient-centred perspective. }\end{array}$ \\
$\begin{array}{l}\text { These are concepts that generalize the healthcare activity class. They are useful in the } \\
\text { Provider activity }\end{array}$ & $\begin{array}{l}\text { Healthcare context to specify the type of actor that provide the service. Not useful in the social } \\
\text { setting given that services are provided only by social care professionals and organizations. } \\
\text { Health issue }\end{array}$ & $\begin{array}{l}\text { These two concepts are used in the relevant context to model the care condition of the } \\
\text { subject of care. They are modelled using two different classes that can be related with each } \\
\text { other to specify whether a health issue can determine a social need. } \\
\text { If an automated activity is delivered this concept identifies the device involved in its } \\
\text { performance. No automated activities are expected in the social care context. }\end{array}$ \\
\hline
\end{tabular}


Table 6: List of concepts that are straightforward mapped with the FHIR resources.

\begin{tabular}{|c|c|c|}
\hline ContSys & FHIR & Description of FHIR resource(s) \\
\hline $\begin{array}{l}\text { Healthcare } \\
\text { Professional }\end{array}$ & $\begin{array}{l}\text { AdministrativeResources. } \\
\text { Individuals. Practitioner }\end{array}$ & $\begin{array}{l}\text { A person who is directly or indirectly involved in the provisioning of healthcare. Practitioner } \\
\text { role = A specific set of Roles/Locations/specialties/services that a practitioner may perform } \\
\text { at an organization for a period of time. }\end{array}$ \\
\hline $\begin{array}{l}\text { Healthcare } \\
\text { Organization }\end{array}$ & Base. Entities. Organization & $\begin{array}{l}\text { A formally or informally recognized grouping of people or organizations formed for the } \\
\text { purpose of achieving some form of collective action. Includes companies, institutions, } \\
\text { corporations, departments, community groups, healthcare practice groups, etc. }\end{array}$ \\
\hline Care Plan & $\begin{array}{l}\text { Clinical. Care provision. Care } \\
\text { Plan }\end{array}$ & $\begin{array}{l}\text { Describes the intention of how one or more practitioners intend to deliver care for a } \\
\text { particular patient, group or community for a period of time, possibly limited to care for } \\
\text { a specific condition or set of conditions. }\end{array}$ \\
\hline Third Party & $\begin{array}{l}\text { AdministrativeResources. } \\
\text { Individuals RelatedPerson }\end{array}$ & $\begin{array}{l}\text { Information about a person that is involved in the care for a patient, but who is not the } \\
\text { target of healthcare, nor has a formal responsibility in the care process }\end{array}$ \\
\hline $\begin{array}{l}\text { Episode of } \\
\text { care }\end{array}$ & $\begin{array}{l}\text { Workflow. Encounters. Episode } \\
\text { of care }\end{array}$ & $\begin{array}{l}\text { An association between a patient and an organization / healthcare provider(s) during } \\
\text { which time encounters may occur. The managing organization assumes a level of } \\
\text { responsibility for the patient during this time. }\end{array}$ \\
\hline Contact & Workflow. Encounters. Encounter & $\begin{array}{l}\text { An interaction between a patient and healthcare provider(s) for the purpose of providing } \\
\text { healthcare service(s) or assessing the health status of a patient }\end{array}$ \\
\hline Other Person & $\begin{array}{l}\text { AdministrativeResources. } \\
\text { Individuals Related Person }\end{array}$ & $\begin{array}{l}\text { Information about a person that is involved in the care for a patient, but who is not the } \\
\text { target of healthcare, nor has a formal responsibility in the care process }\end{array}$ \\
\hline Group & $\begin{array}{l}\text { AdministrativeResources. } \\
\text { Groups. Group }\end{array}$ & $\begin{array}{l}\text { Represents a defined collection of entities that may be discussed or acted upon } \\
\text { collectively but which are not expected to act collectively and are not formally or legally } \\
\text { recognized; i.e. a collection of entities that isn't an Organization. }\end{array}$ \\
\hline Health issue & Clinical. General. Condition & $\begin{array}{l}\text { A clinical condition, problem, diagnosis, or other event, situation, issue, or clinical } \\
\text { concept that has risen to a level of concern. }\end{array}$ \\
\hline Device & $\begin{array}{l}\text { AdministrativeResources. Device. } \\
\text { Device }\end{array}$ & $\begin{array}{l}\text { This resource identifies an instance or a type of a manufactured item that is used in } \\
\text { the provision of healthcare without being substantially changed through that activity } \\
\text { The device may be a medical or non-medical device. Medical devices include durable } \\
\text { (reusable) medical equipment, implantable devices, as well as disposable equipment } \\
\text { used for diagnostic, treatment, and research for healthcare and public health. Non- } \\
\text { medical devices may include items such as a machine, cell phone, computer, application, } \\
\text { etc. }\end{array}$ \\
\hline & $\begin{array}{l}\text { \& AdministrativeResources. } \\
\text { Device. Component }\end{array}$ & $\begin{array}{l}\text { Device component }=\text { The characteristics, operational status and capabilities of a } \\
\text { medical-related component of a medical device }\end{array}$ \\
\hline
\end{tabular}

Table 7: FHIR resources that have to be accommodated to be mapped with the relevant H@H concept.

\begin{tabular}{llll}
\hline \multicolumn{1}{c}{ Concept } & \multicolumn{1}{c}{ FHIR resource } & \multicolumn{1}{c}{ Definition of the resource } & \multicolumn{1}{c}{ Accommodation } \\
$\begin{array}{l}\text { General } \\
\text { Practitioner }\end{array}$ & $\begin{array}{l}\text { Base. Individuals. Practitioner } \\
\text { + Practitioner Role } \\
\text { Clinical. General. Condition }\end{array}$ & $\begin{array}{l}\text { A person who is directly or indirectly } \\
\text { involved in the provisioning of healthcare. } \\
\text { A clinical condition, problem, diagnosis, } \\
\text { or other event, situation, issue, or clinical } \\
\text { concept that has risen to a level of concern. }\end{array}$ & $\begin{array}{l}\text { The role of the practitioner is set to GP. } \\
\text { Condition refers to health problems. So } \\
\text { this resource should be accommodated to } \\
\text { describe social needs at least in terms of } \\
\text { vocabulary as well as nomenclatures. }\end{array}$ \\
$\begin{array}{llll}\text { Social care } \\
\text { Professional }\end{array}$ & $\begin{array}{l}\text { AdministrativeResources. } \\
\text { Individuals. Practitioner }\end{array}$ & $\begin{array}{l}\text { A person who is directly or indirectly } \\
\text { involved in the provisioning of healthcare. } \\
\text { Practitioner role A specific set of Roles/ } \\
\text { Locations/specialties/services that a } \\
\text { practitioner may perform at an organization } \\
\text { for a period of time. }\end{array}$ & $\begin{array}{l}\text { Extends the vocabulary items to include } \\
\text { the type of social care practioner }\end{array}$ \\
& & &
\end{tabular}

that can be straightforward mapped with the concepts of to facilitate the information exchange in a continuity of care the H@H schema (Table 6), FHIR resources that have to perspective.

be accommodated to map with the relevant concept of the H@H schema (Table 7) and resources that have to be extended to capture the information of the relevant $\mathrm{H} @ \mathrm{H}$ concept (Table 8). As previously highlighted, this mapping exercise is an important first step to verify to what extent the ContSys concepts can be integrated with the FHIR resources
Table 7 and 8 highlight on the one hand the need of capturing through the use of a standard the context and context of the ContSys concepts to improve the integration between the health and social care. On the other hand, the feasibility of the proposed approach should be verified 
Table 7 (cont'd): FHIR resources that have to be accommodated to be mapped with the relevant H@H concept.

\begin{tabular}{lll}
\hline \multicolumn{1}{c}{ Concept } & \multicolumn{1}{c}{ FHIR resource } & \multicolumn{1}{c}{ Definition of the resource } \\
\hline $\begin{array}{l}\text { Social care } \\
\text { Organization }\end{array}$ & Base. Entities. Organization & $\begin{array}{l}\text { A formally or informally recognized grouping of people Extends the vocabulary } \\
\text { or organizations formed for the purpose of achieving items to include the type of } \\
\text { some form of collective action. Includes companies, social care organization } \\
\text { institutions, corporations, departments, community } \\
\text { groups, healthcare practice groups, etc. }\end{array}$ \\
Location & $\begin{array}{l}\text { Administrative Resources. } \\
\text { Entities. Location }\end{array}$ & $\begin{array}{l}\text { Details and position information for a physical Extends the vocabulary } \\
\text { place where services are provided and resources items to include the type of } \\
\text { and participants may be stored, found, contained or social care delivery location } \\
\text { accommodated. }\end{array}$ \\
\hline
\end{tabular}

Table 8: List of FHIR resources that have to be extended to be mapped with the relevant H@H concept.

\begin{tabular}{|c|c|c|c|}
\hline Concept & FHIR resource & Definition of the resource & Extension \\
\hline Subject of care & $\begin{array}{l}\text { Aministrative Resources. } \\
\text { Individuals. Patient }\end{array}$ & $\begin{array}{l}\text { Demographics and other administrative } \\
\text { information about an individual or animal } \\
\text { receiving care or other health-related services }\end{array}$ & $\begin{array}{l}\text { Includes attributes specifically devoted to } \\
\text { capture social and economic status. }\end{array}$ \\
\hline $\begin{array}{l}\text { Healthcare } \\
\text { Activity }\end{array}$ & $\begin{array}{l}\text { Clinical. General. } \\
\text { Procedure }\end{array}$ & $\begin{array}{l}\text { An action that is or was performed on a patient. } \\
\text { This can be a physical intervention like an } \\
\text { operation, or less invasive like counselling or } \\
\text { hypnotherapy }\end{array}$ & $\begin{array}{l}\text { Includes an attribute to capture the type } \\
\text { of healthcare activity performed (e.g. visit, } \\
\text { lab exam, etc.) }\end{array}$ \\
\hline Social Activity & $\begin{array}{l}\text { Clinical. General. } \\
\text { Procedure }\end{array}$ & $\begin{array}{l}\text { An action that is or was performed on a patient. } \\
\text { This can be a physical intervention like an } \\
\text { operation, or less invasive like counselling or } \\
\text { hypnotherapy }\end{array}$ & $\begin{array}{l}\text { Includes an attribute to capture the type } \\
\text { of social activity performed (e.g. cleaning, } \\
\text { good provision, etc.) }\end{array}$ \\
\hline $\begin{array}{l}\text { Automated; } \\
\text { Contributing; } \\
\text { Self; Provider } \\
\text { activity }\end{array}$ & $\begin{array}{l}\text { Clinical. General. } \\
\text { Procedure }\end{array}$ & $\begin{array}{l}\text { An action that is or was performed on a patient. } \\
\text { This can be a physical intervention like an } \\
\text { operation, or less invasive like counselling or } \\
\text { hypnotherapy }\end{array}$ & $\begin{array}{l}\text { The type of activity is not specified within } \\
\text { the Procedure resources but it can be } \\
\text { detected on the basis of the provider } \\
\text { (Device for Automated, Related Person for } \\
\text { contributing, Patient for self-activity and } \\
\text { Practitioner for provider). However, an } \\
\text { additional attribute can help identifying } \\
\text { this information. }\end{array}$ \\
\hline
\end{tabular}

considering the standards under development, such as the ISO 13606-3:2017 [21].

\section{Conclusions}

The paper describes the $\mathrm{H} @ \mathrm{H}$ conceptual model integrating the social care with the health care concepts. This was designed on the basis of the ContSys standard deployed in the healthcare context to improve the continuity of care. The semantic interoperability is assured through the use of the HL7 FHIR standard framework that also improves the coordination and cooperation activities of the different stakeholders involved in the provision of services in an comprehensive continuity of care process. Our model is a starting point to analyse the various determinants of care able to guarantee a high-level of individual's quality of life. As previously highlighted, this mapping exercise is an important first step to verify to what extent the ContSys concepts can be integrated with the FHIR resources to facilitate the information exchange in a continuity of care perspective. Considering that the FHIR the infrastructure has been proved to be stable while the resources are still subject to improvements [16] our work was a necessary test to capture feasible resources that conform to the content and context of the ContSys concepts. Of course the introduction of these resources and/or the introduction of new ones should be subject to significant review through ballot and other HL7 processes. Moreover, we intend to analyse the ISO 13606$3: 2017$ [21] which at the moment is under development to further improve the methodology in the perspective of identifying clinical archetypes.

At the moment $\mathrm{H} @ \mathrm{H}$ information system is at the implementation phase. During its implementation and also the next deployment the evaluation of social technological alignment will be also is taken into account to establish a shared understanding between the social context and the software domain.

\section{Acknowledgements}

This work is part of the H@H (Health At Home) - Smart Communities for the wellbeing of the citizens - project granted within the National Operational Programme for Research and Competitiveness 2007-2013. Identification code: SCN_00558. 


\section{References}

[1] Goodwin N, Dixon A, Anderson G, Wodchis W. Providing integrated care for older people with complex needs: lessons from seven international case studies. London: The King's Fund. 2014.

[2] Home-based and long-term care: home care issues and evidence. Geneva, World Health Organization, 1999. Available from: www.who. int/chp/knowledge/publications/Chronic_conditions/en/index.html

[3] Tarricone R, Agis TD. Home care in Europe: the solid facts. WHO Regional Office Europe. 2008.

[4] Lindberg B, Nilsson C, Zotterman D, Söderberg S, Skär L. Using information and communication technology in home care for communication between patients, family members, and healthcare professionals: A systematic review. Int J Telemed Appl. 2013.

[5] Clarfield M, Bergman H, Kane R. Fragmentation of care for frail older people-an international problem. Experience from three countries: Israel, Canada, and the United States. J Am Geriatr Soc. 2001; 49: 1714-1721.

[6] Boerma W, Kroneman M, Hutchinson A, Saltman RB. Home care across Europe. N. Genet (Ed.). London: European Observatory on Health Systems and Policies. 2013.

[7] Landi F, Onder G, Russo A, Tabaccanti S, Rollo R, Federici S, Tua E, Cesari M, Bernabei R. A new model of integrated home care for the elderly: impact on hospital use. J Clin Epidemiol. 2001; 54: 968-970.

[8] Chan M, Campo E, Estève D, Fourniols JY. Smart homes-current features and future perspectives. Maturitas. 2009; 64: 90-97.

[9] Home - The Best Place for Health Care. A positioning statement from The Joint Commission on the state of the home care industry. Available from: http://www.jhartfound.org/images/uploads/resources/Home_ Care_position_paper_4_5_111.pdf

[10] Kok L, Berden C, Sadiraj K. Costs and benefits of home care for the elderly versus residential care: a comparison using propensity scores. Eur J Health Econ. 2015; 16: 119-131.
[11] Shepperd S, Iliffe S. Hospital at home versus in-patient hospital care. Cochrane Database Syst Rev. 2005; 3.

[12] Community home-based care in resource-limited settings: a framework for action. Geneva, World Health Organization, 2002. Available from: www.who.int/chp/knowledge/publications/Chronic_conditions/en/ index.html

[13] International Organization for Standardization. ISO 13940: Health Informatics - System of Concepts to Support Continuity of Care (ContSys). Geneva: ISO; 2015.

[14] Benson T. SNOMED CT. Principles of Health Interoperability HL7 and SNOMED. 2010.

[15] Schadow G, Mead CN. The HL7 Reference Information Model under scrutiny. Stud Health Technol Inform. 2007; 124: 151-156.

[16] Health Level Seven, Inc. FHIR: Fast healthcare interoperability resources. Available from: http://hl7.org/implement/standards/fhir/

[17] Pecoraro F, Luzi D, Pourabbas E, Ricci FL. A conceptual model for integrating social and health care services at home: the $\mathrm{H} @ \mathrm{H}$ project. Proceedings of the 18th International conference on E-Health, Networking, Application and Services, 2016. DOI: 10.1109/ HealthCom.2016.7749489

[18] Pecoraro F, Luzi D, Ricci FL. Secondary uses of EHR systems: A feasibility study. IEEE E-Health and Bioengineering Conference (EHB). 2013; 1-6.

[19] Hägglund M, Chen R, Koch S. Modeling shared care plans using CONTsys and openEHR to support shared homecare of the elderly. J Am Med Inform Assoc. 2011; 18: 66-69.

[20] World Health Organization. Integrated health services: what and why? Health Services Delivery Technical Brief No.1, 2008.

[21] International Organization for Standardization. ISO/DIS 13606-3: Health Informatics - Electronic health record communication - Part 3: Reference archetypes and term lists. Geneva: ISO; 2017. 